DOI 10.19195/2084-2546.27.12

DIEGO RIVADULLA COSTA

ORCID: 0000-0002-0163-8140

Universidade da Coruña

Correo: diego.rivadulla@udc.gal

\title{
As voces dos recordos: memoria oral, pasado traumático e novela na Galiza actual $^{*}$
}

Palabras chave: memoria oral — memoria cultural — novela galega actual — franquismo.

\section{Consideracións previas}

Desde finais dos anos noventa e coincidindo coa entrada no século XXI, vimos asistindo no conxunto do Estado español á eclosión dun boom da memoria que se caracteriza por un rexurdimento do pasado traumático da guerra civil e da ditadura franquista na esfera socio-política, situándose a denominada "recuperación da memoria histórica" no centro do debate público, onde permanece ata a inmediata actualidade. As reivindicacións de xustiza, verdade e reparación para as vítimas do franquismo por parte do amplo movemento asociativo de base social que loita por rematar coa impunidade dos crimes da ditadura na procura dunha xustiza que se vira truncada pola Lei de Amnistía do ano 1977 - e, en xeral, polo "pacto de reconciliación" que rodeou a Transición española - comezan a dar os seus primeiros froitos desde o punto de vista lexislativo coa aprobación da chamada "Lei de memoria histórica" do ano 2007 por parte do goberno socialista de Rodríguez Zapatero" Paralelamente, asistimos á aparición dunha cantidade cada vez maior de traba-

* Este traballo inscríbese no proxecto de investigación doutoral do autor, que contou cunha das axudas de apoio á etapa predoutoral da Consellería de Cultura, Educación e Ordenación Universitaria da Xunta de Galicia do ano 2016.

${ }^{1}$ Ley 52/2007, de 26 de diciembre, por la que se reconocen y amplían derechos y se establecen medidas a favor de quienes padecieron persecución o violencia durante la guerra civil y la dictadura. 
llos historiográficos, ben como de producións culturais e artísticas, que tematizan o pasado recente e contribúen á reflexión sobre a súa memoria e representación.

No caso galego, o movemento memorialista que emerxe desde comezos do século recibiu tamén un importante pulo desde o punto de vista institucional entre os anos 2005 e 2009, durante o goberno bipartito de esquerdas na Xunta de Galicia, que levou a cabo por primeira vez unha auténtica política da memoria no país, como apunta Lourenzo Fernández Prieto ${ }^{2}$. Algúns fitos destacables foron, por exemplo, a conmemoración no 2006 do "Ano da Memoria", as exposicións e homenaxes aos represaliados da ditadura, o financiamento de iniciativas a prol da recuperación da memoria, a publicación de volumes conmemorativos ou a posta en marcha do proxecto de investigación interuniversitario "As vítimas, os nomes e as voces", entre cuxos obxectivos principais estaba a construción dun fondo oral para o estudo da guerra civil e a represión en Galiza a través da recollida do relato dos protagonistas, das vítimas e dos seus descendentes ${ }^{3}$. Podemos dicir, pois, que as memorias da represión que sucedeu ao golpe de Estado de 1936, que durante décadas permaneceran ocultadas e que se conservaran e renovaran oralmente - de maneira case clandestina - no ámbito familiar e privado, onde se transmitiran aos descendentes das vítimas, comezan a ser apreciadas como unha fonte de coñecemento útil para a sociedade por parte dunha xeración máis nova - maioritariamente a dos chamados "netos da guerra", que non asinara o acordo social da Transición - a quen interesa o que pasou, recuperar a memoria e incorporala ao coñecemento histórico, falseado por anos de memoria oficial da ditadura ${ }^{4}$.

A literatura, pola súa parte, como discurso social, e en especial a narrativa, como xénero máis apropiado "para brindar experiencias de inmersión na memoria histórica", xa se viña ocupando timidamente da representación do pasado traumático da guerra e a ditadura desde a pioneira Non agardei por ninguén de Ramón de Valenzuela (publicada en 1957 no exilio bonaerense) e desde a mesma Transición coas primeiras autobiografías noveladas de Silvio Santiago - O silencio redimido, 1976- ou Antón Alonso Ríos - O siñor Afranio ou como me rispei das gadoupas da morte, 1979-. No entanto, agora vese condicionada por este novo contexto da cultura da memoria emerxente, desenvolvéndose a partir do ano 2000 unha prolífica nova novela galega da memoria que amosa, a respecto da anterior, unha considerable evolución nos

${ }^{2}$ L. Fernández Prieto, "Actitudes sociales y políticas en la denominada recuperación de la memoria histórica. Galicia. El proyecto de investigación interuniversitario «Nomes e voces»", Pasado y Memoria, 8, 2009, p. 141.

${ }^{3}$ Ibidem, p. 147.

${ }^{4}$ A. Domínguez, A. Somoza, "Víctimas y memoria del 36: De la resistencia callada al voto en la transición”, Memória Antifranquista Del Baix Llobregat, 9 (13), 2013, p. 77.

5 J. Thompson, As novelas da memoria. Trauma e representación da historia na Galiza contemporánea, Vigo, Galaxia, 2009, p. 11. 
modos de representación e fórmulas empregadas no tratamento do pasado recente, tal e como ten apuntado Dolores Vilavedra ${ }^{6}$.

Obras premiadas e aclamadas pola crítica como Expediente Artieda (2000) de Luís Rei Núñez, Home sen nome (2006) de Suso de Toro, Sol de Inverno (2009) de Rosa Aneiros ou Non hai noite tan longa (2011) de Agustín Fernández Paz — por citarmos só uns poucos exemplos representativos - articulan a memoria silenciada da guerra civil e do franquismo, desenvolvendo temas como a dura represión de posguerra, as dificultades da loita antifranquista ou a herdanza do trauma causado polo fascismo. E fano, ademais, desde novas perspectivas e a través de novos modos narrativos que lles permiten ir máis alá da función de recuperación de historias e memorias silenciadas que lle tiña sido tradicionalmente atribuída a esta literatura, para reflexionaren tamén sobre a recuperación da memoria histórica por parte das novas xeracións ou sobre os procesos de transmisión interxeracional desas memorias silenciadas durante décadas.

\section{A construción da memoria cultural e a reconstrución literaria do pasado traumático en Galiza}

Neste contexto, unha ollada aos denominados Estudos de memoria cultural, que se teñen constituído tamén coa entrada no novo milenio como un prolífico campo de investigación interdisciplinar que se ve alimentado pola continua aparición de novos produtos culturais que analizar ${ }^{7}$, permite botar luz sobre o caso do pasado traumático galego e a importancia da novela na construción da memoria cultural contemporánea. Entre as achegas que xurdiron neste campo seguindo o camiño iniciado por Maurice Halbwachs na súa caracterización da memoria como acto colectivo e social, destacan especialmente os traballos de Jan Assmann, que ten distinguido dúas formas de manifestación da memoria colectiva: a memoria comunicativa e a cultural. A primeira estaría baseada nos recordos persoais das testemuñas, que se articulan e se transmiten no discurso oral, na comunicación cotiá de maneira espontánea e nunha linguaxe informal. Trátase, por tanto, da memoria do recordo vivo, que un individuo comparte cos seus coetáneos, de maneira que o seu alcance temporal se limita a uns 80 ou 100 anos e entre tres e catro xeracións. Fronte a ela, a memoria cultural sería aquela constituída dentro duns marcos

${ }^{6}$ Para unha completa cronoloxía da evolución do tratamento literario do tema en Galiza, véxase este ou outros traballos da especialista: D. Vilavedra, "Literatura en el espacio público. Rivas y su obra: un punto de inflexión en la recuperación de la memoria histórica", Olivar, 16 (24), 2015, pp. $1-17$.

${ }^{7}$ Para unha introdución á teorización do campo de estudo véxase: A. Erll, "Cultural Memory Studies. An Introduction”, en: A. Erll, A. Nünning (eds.), Cultural Memory Studies. An International and Interdisciplinary Handbook, Berlin-New York, Walter de Gruyter, 2008, pp. 1-18. 
culturais, unha historia rememorada que non se basea en vivencias e que se constrúe, se forma e se fixa a través de representacións simbólicas en diversos soportes para perdurar ao longo de séculos ${ }^{8}$.

De acordo coa diferenciación assmánnica, semella pertinente afirmarmos, seguindo a Elina Liikanen, que a sociedade galega, como a española, estaría a atravesar nos comezos do século XXI algo así como unha transición da memoria comunicativa cara á memoria cultural, coa desaparición progresiva da xeración que protagonizou a guerra e a represión de posguerra - e dos seus testemuños orais - e a paralela aparición do movemento memorialista na cultura e na sociedade ${ }^{9}$, un contexto en que o labor dos novelistas viría ser fundamental, pois contribuirían a fixar a través dun medio escrito a memoria colectiva dun pasado cada vez máis afastado. Neste sentido, concordamos con Astrid Erll en que a literatura, como a historiografía ou os medios de cultura visuais, poden chegar a constituír potentes "medios de memoria" que desenvolvan as funcións de almacenamento e circulación de recordos culturais, é dicir, medios a través dos cales se constrúe a memoria cultural dun determinado grupo, contexto e lugar ${ }^{10}$. Coidamos, por tanto, que a novela galega obxecto da nosa análise constitúe un deses medios que, en pleno contexto memorialista e no momento de desaparición das últimas testemuñas, colaboran na construción da memoria colectiva da sociedade galega actual sobre o pasado franquista.

De acordo co anterior, para Hansen, a novela actual dedicada á rememoración da guerra e o franquismo participa do diálogo multivocal e multidireccional que ten lugar na esfera pública do Estado español e as súas rexións a través do cal —ou dos cales- se está a negociar a forma de comprender a realidade política, cultural e social a partir da interpretación da historia recente $^{11}$. Segundo o especialista danés, este diálogo sobre o pasado entre discursos sociais do presente non fai senón incidir na forma de contar do discurso novelístico e na forma de este plasmar os universos ficticios, o que explicaría, por exemplo, que abunden o número de narracións que responden á estrutura da nova novela histórica, isto é, que se caracterizan por proporen un diálogo entre dous planos temporais $-\mathrm{o}$ pasado histórico que se pretende rescatar e un marco da narración que se localiza na actualidade desde o que o pasado

8 J. Assmann, "Communicative and Cultural Memory", en: A. Erll, A. Nünning (eds.), op. cit., pp. 109-118.

${ }^{9}$ E. Liikanen, "Pasados imaginados. Políticas de la forma literaria en la novela española sobre la guerra civil y el franquismo", en: H.L. Hansen, J.C. Cruz Suárez (eds.), La memoria novelada. Hibridación de géneros y metaficción en la novela española sobre la guerra civil y el franquismo (2000-2010), Berna, Peter Lang, 2012, p. 43.

${ }^{10}$ Cómpre sinalarmos, no entanto, que Erll cuestiona a distinción polarizante presentada por Assmann e concibe a memoria cultural dunha maneira moito máis ampla, como toda forma de rememoración, de interacción entre presente e pasado, que ten lugar en contextos socioculturais específicos. A. Erll, Memory in Culture, Hampshire, Palgrave Macmillan, 2011.

${ }^{11}$ H.L. Hansen, "Formas de la novela histórica actual", en: H.L. Hansen, J.C. Cruz Suárez (eds.), op. cit., p. 83. 
se reconstrúe - a través do cal pretenden describir, discutir e reflexionar sobre os procesos sociais que contribúen á produción dunha memoria cultural nunha determinada sociedade ${ }^{12}$.

Esta estrutura dialóxica pasado-presente, que Luengo ten denominado "novela de confrontación histórica"13 e Liikanen "modo reconstrutivo" da novela da memoria ${ }^{14}$, é tamén un procedemento recorrente da nova novela galega que participa do boom memorialista, en cuxas tramas xoga un papel fundamental o proceso de "transmisión del testimonio y la cuestión de en qué medida la memoria puede ser legada, de manera verídica de una generación a la otra"15. A transmisión da(s) memoria(s) revélase así como unha preocupación central nos autores da terceira xeración, influídos polo contexto en que producen e, probablemente, debido a que se senten cada vez máis afastados dos feitos históricos narrados ${ }^{16}$. Tal e como sinala Mariela Sánchez, co obxectivo de configurar unha memoria do pasado traumático, a narrativa memorialística pon en escena diferentes modalidades de transmisión oral, converxendo unha innegábel nostalxia pola desaparición de fontes de oralidade cunha demostración de procedementos estéticos que reciclan esas fontes e as reflotan, ao tempo que evidencian o problema da súa extinción ${ }^{17}$.

A ficcionalización da memoria oral das testemuñas e a escenificación da súa transmisión ás seguintes xeracións que non viviran os feitos de maneira directa e que queren romper co silencio e esquecemento imperantes simboliza nestas novelas non só as dificultades da recuperación da memoria histórica no novo milenio, senón tamén a transformación da memoria comunicativa en memoria cultural, proceso que os textos ilustran e ao que contribúen a un tempo ${ }^{18}$. Nas liñas que seguen ocuparémonos desta cuestión na nova narrativa galega da memoria xurdida nos últimos anos.

\section{As representacións da memoria oral na novela galega actual}

Como vimos de mencionar, é especialmente —aínda que non de maneira exclusiva - nese tipo de novelas en que conviven dous planos temporais onde máis frecuentemente atopamos a representación da memoria oral como

12 Ibidem, p. 89.

${ }^{13}$ A. Luengo, La encrucijada de la memoria, Berlín, Tranvía, 2012.

${ }^{14}$ E. Liikanen, op. cit., p. 47.

${ }^{15}$ M. Albert, "Oralidad y memoria en la novela memorialística", en: U. Winter (ed.), Lugares de memoria de la guerra civil y el franquismo, Madrid-Frankfurt, Iberoamericana-Vervuert, 2006, p. 21.

16 J. Thompson, op. cit., p. 60.

${ }^{17}$ M. Sánchez, Mala herencia la que nos ha tocado: oralidad y narrativa en la literatura sobre la Guerra Civil y el franquismo, Santiago de Compostela, USC Editora Académica, 2018, p. 276 e 284.

${ }^{18}$ M. Albert, op. cit., p. 22. 
única forma de pervivencia do pasado na actualidade e, por tanto, como única maneira de acceder a el. Así, cando ambos niveis — presente e pasado- conviven na narración, é habitualmente esa memoria a que asume o papel principal á hora de presentar os eventos pasados, adquirindo un importante rol a nivel diexético, como anota Kortazar $^{19}$. Seguindo a terminoloxía assmánnica, podemos dicir que é en moitos casos a memoria comunicativa a que asume a función de conexión entre ambos niveis temporais no interior da diéxese, de modo que non só se tematiza a transmisión dos recordos a través da oralidade, senón que esta funciona como mecanismo discursivo ${ }^{20}$, introducindo en ocasións, ademais, un relato intercalado ou metadiexético.

Como corresponde, nestas historias son habitualmente as personaxes de máis idade - as testemuñas do tempo que se pretende recuperar - as portadoras dunha memoria viva, que na maioría dos casos permanecía reprimida e silenciada ata ese momento, as encargadas de narralo e de traelo ata a actualidade para o rescatar e deixar constancia del. E, habitualmente tamén, os receptores desas memorias - e en moitas ocasións instigadores da transmisión - son personaxes representantes da terceira ou cuarta xeración que actúan de narratarios internos da(s) historia(s) que a novela rescata e cos que é frecuente, por tanto, que o lector se sinta identificado. A seguir revisaremos algunhas das novelas memorialísticas galegas sobre o golpe de 1936, a represión franquista ou a resistencia antifranquista publicadas nos últimos anos para exemplificarmos estas consideracións e analizarmos a forma en que nelas se manifesta a memoria oral. Centrarémonos especialmente no papel central adquirido por esa oralidade ficcionalizada, convertida incluso no elemento vertebrador de moitas das obras.

O relato d'O lapis do carpinteiro (1998) de Manuel Rivas, referente da memoria novelada en Galiza, arranca cando un xornalista visita ao ancián Daniel Da Barca, vítima da represión e o exilio regresado a Galiza, para o entrevistar e recoller a súa memoria por escrito para a publicar no xornal onde traballa. Porén, o lector finalmente non coñece a historia de Da Barca a través da reportaxe, senón grazas a unha especie de confesión oral de Herbal, o vitimario franquista, torturador e asasino dos presos republicanos compañeiros de Da Barca. Atopamos, por tanto, un marco da narración situado na contemporaneidade onde o narrador heterodiexético traduce en escritura a rememoración oral do garda Herbal, tal e como ten analizado Ana Bungård, de modo que a orixinal fórmula narrativa empregada por Rivas permite, segundo a crítica, relatar con verosimilitude desde a percepción contemporánea a memoria comunicativa das vítimas da guerra civil en Galiza ${ }^{21}$. Neste sentido, Vilavedra sinala tamén que a única forma coherente de restaurar a fractura enunciativa que se produce na

19 J. Kortazar, "Memoria y Guerra civil en la narrativa vasca (1948-2007)", en: Repositorio institucional UNLP, 2008, <http://sedici.unlp.edu.ar/handle/10915/16283>, 26 de abril de 2018.

${ }^{20}$ M. Albert, op. cit., p. 22.

${ }^{21}$ A. Bungård, "Registros de la imaginación utópica en la ficción memorialista española actual: El lápiz del carpintero, Soldados de Salamina y Anatomía de un instante", en: H.L. Hansen, J.C. Cruz Suárez (eds.), op. cit., p. 116. 
novela desde o primeiro capítulo é entender que Herbal lle conta a súa historia a María da Visitaçao e que esta lla narra ao xornalista Carlos, convertido en cliente $^{22}$.

Na novela Home sen nome (2006), unha das máis destacadas achegas de Suso de Toro ao corpus da ficción memorialística galega, o autor presenta unha acción principal que se desenvolve nun hospital actual de Santiago de Compostela, onde comparten habitación un mozo - que fai as veces de interlocutor- e un vello fascista de case cen anos que agoniza. Neste caso son os delirios, reflexións e diálogos do ancián os que constitúen a vía do acceso ao pasado dentro da novela, ao segundo plano temporal. A memoria oral desde permite ao lector coñecer a súa espantosa biografía: formado no Berlín próximo á ascensión de Hitler, ao que apoia con convicción, volvera a España para se unir aos grupos fascistas que preparaban o golpe de estado e poder levar a cabo a "limpeza" do país; tras loitar na guerra civil e decepcionado coa nova España de Franco, incorpórase á División Azul para seguir loitando. As conversas que mantén o personaxe cunha escritora, que acode ao hospital moi interesada no seu testemuño porque anda a preparar un documental sobre a traumática historia das Marías compostelás, son o medio perfecto - de novo o recurso da entrevista - para que esa memoria oral se despregue no plano actual. A historia do vello verase reflectida no documental, un produto cultural do novo milenio, como na novela de De Toro, de modo que a metaficción explicita aquí o paso da memoria oral e viva á memoria cultural que representarían ambas producións: o fictivo documental e a novela real.

Especialmente curioso resulta tamén o caso da obra Escapados nos eidos das Foucellas (2007) de Andrés Mariño Sanmartín, onde atopamos un primeiro nivel da narración localizado na contemporaneidade do ano 1990 e que constitúe o marco das historias que se desenvolven no segundo nivel narrativo, localizadas entre os anos 1919 e 1963. Neste marco da narración asistimos á celebración dun velorio en que se produce unha conversa entre tres personaxes, Carmiña, Raquel e Dosinda, onde a primeira asume o papel de narradora - e as demais, en consecuencia, de interlocutoras - das historias do pasado que virían explicar a maldición causante da morte do defunto. Deste xeito, a memoria oral de Carmiña, unha muller de 80 anos que sufrira a posguerra e vivira de preto as historias dos escapados, dá lugar a ese segundo nivel narrativo en que adquire o papel de narradora e en que se desenvolve unha historia relacionada co famoso guerrilleiro galego Benigno Andrade, coñecido como o Foucellas. Carmiña é a voz da memoria daquela época, que traslada aos interlocutores no velorio, e xa no capítulo final da novela sabemos que foi tamén ela quen, con 90 anos, contou a historia ao narrador heterodiexético do primeiro nivel narrativo e autor implícito da novela. A memoria oral funciona, por tanto, a través da personaxe na propia historia, mais tamén, de maneira metaficcional, como fonte para a novela que se constrúe grazas a ese testemuño.

${ }^{22}$ D. Vilavedra, op. cit., p. 9. 
Pola súa parte, a obra Na solaina (2008), de David D. Vázquez Álvarez, narra a historia de Ana, unha sexaxenaria que chega en ambulancia a unha residencia de maiores na que fora a súa aldea natal para recuperarse dunha operación. A viaxe supón un reencontro co seu pasado, unha biografía que a personaxe traslada ao lector a través das súas conversas con Diana, unha das enfermeiras do centro. De novo, no contexto das informais entrevistas que se producen entre paciente e coidadora, desprégase a memoria oral da protagonista sobre a súa infancia e a súa historia de amor con Daniel, o Rabizo, nos anos 30, que se vira condicionada polo inicio da guerra civil e a fuxida deste ao monte, primeiro, e logo a Francia, onde rematou no campo de concentración de Mauthausen. As vivencias - estas xa descoñecidas por Ana - deste personaxe no campo e durante o seu posterior exilio cubano completan unha historia que remata co reencontro dos protagonistas no mesmo lugar da infancia. Aínda que se mantén un narrador omnisciente heterodiexético ao longo de toda a novela, son facilmente recoñecibles as partes que corresponden á vida da protagonista, pois xorden a partir desas conversas en que Ana fai memoria para explicarlle á enfermeira o seu pasado.

Con todo, aínda cando o discurso de memoria oral non ocupe no interior da diéxese un papel tan protagónico á hora de despregar un relato secundario localizado no pasado, quere dicir, cando non é a personaxe portadora de memoria a que se converte en enlace entre os dous planos temporais en que se desenvolve a historia, chegando a depender del a estrutura da novela, é frecuente a aparición dun personaxe na novela que se erixe como representante da memoria aínda viva do pasado da guerra civil ou da posguerra, cuxas vivencias son transmitidas oralmente a outro(s) personaxes de xeracións posteriores que participan na acción. É o caso, por exemplo, do vello Mateo Lan en Expediente Artieda (2000) de Luís Rei Núñez, un cego que, na Coruña dos anos 50 onde se localiza a acción, representa a memoria da Segunda República e do golpe de estado do 36, contando historias de presos e asasinados a mans dos fascistas no parladoiro clandestino en que se converte a tenda de Fotos Querentes, onde o máis interesado é Camilo, un rapaz novo que ansía con vingar a morte do pai, unha das tantas vítimas do franquismo.

Do mesmo modo, cando as novelas se basean nunha trama de investigación que pretende resolver algún misterioso caso relacionado co pasado recente, tematizando así a recuperación contemporánea da memoria histórica, as testemuñas orais convértense en elementos fundamentais no labor levado cabo polos protagonistas das obras, convertidos en "detectives da memoria" 23 . Nestes casos, tal e como sinala Albert, "el núcleo de la investigación lo constituye, las más de las veces, el testimonio oral de algún testigo de la época como último eco del "tiempo perdido" que el novelista-documentalista capta en su intento de dar voz al pasado" 24 . Así o vemos, por exemplo, n'O tempo

${ }^{23}$ J. Sánchez Zapatero, "Detectives de la memoria: la novela negra como medio de indagación en la historia reciente española", Ciberletras, 26, 2016.

${ }^{24}$ M. Albert, op. cit., p. 22. 
en ningunha parte (2003), de Xosé Manuel Martínez Oca, onde atopamos unha acción principal narrada en primeira persoa polo seu protagonista, un técnico de minas que chega por motivos laborais ao Portelo da Moura, no interior de Ourense, e decide comezar a investigar a historia de Tomás Pazos, un veciño que fora deputado durante a Segunda República, exiliado en Bos Aires a partir do 1936 e que regresara á vila a comezos dos cincuenta. No entanto, o que atopa o narrador-protagonista é unha sociedade atrasada e amnésica que en moitos aspectos continúa ancorada no franquismo. $\mathrm{O}$ silencio arredor da figura de Pazos dificulta enormemente a investigación iniciada, e a falta de fontes documentais sobre o investigado fai que a memoria oral dalgún veciño sexa a única maneira de acceder a un pasado que o narrador decide contar por escrito nunha metaficción que se incorpora como parte da novela.

Dun modo similar funciona tamén a novela Non hai noite tan longa (2011), onde Agustín Fernández Paz propón un relato de investigación protagonizado por Gabriel Lamas, un home de cincuenta anos que no seu regreso a Galiza no ano 2002 recibe a visita do espectro do seu pai falecido reclamando xustiza e decide emprender unha investigación para descubrir a verdade que rodeara o encarceramento e a morte daquel nos anos sesenta e reparar así a súa memoria. As dificultades con que se vai atopar ao longo do proceso, principalmente relacionadas co silencio e a complicidade dunha sociedade que decidiu calar ante a inxustiza, son solventadas pola excepción que constitúe a memoria oral dalgúns personaxes da vila, especialmente do avogado que levara o caso, quen achega o principal testemuño daquel tempo convulso en que o pai de Gabriel fora inxustamente culpado dunha violación só polas súas ideas políticas. Así, ao longo da novela as entrevistas do protagonista co letrado convértense en auténticos discursos da memoria viva do pasado que se pretende reconstruír.

\section{Consideracións finais}

No seu estudo do tratamento da guerra civil na novela española contemporánea, significativamente subtitulado "Silencio y diálogo entre generaciones", María Corredera González parte da seguinte constatación, que coidamos é ilustrativa das ideas recollidas ata o momento no noso traballo:

Actualmente existe un proceso inverso al de la transición y las primeras décadas de democracia respecto al silencio de las víctimas; hoy se busca conocer el pasado mediante los testimonios de los testigos, de ahí la importancia que tiene la palabra del testigo. Estamos viviendo en los límites de una época, en la que están desapareciendo los testigos y las víctimas de la guerra civil y la represión franquista, y donde en breve no quedarán testigos que puedan rememorar sus experiencias personales, y sus recuerdos tendrán que sustentarse en la memoria de las nuevas generaciones ${ }^{25}$.

${ }^{25}$ M. Corredera González, La guerra civil española en la novela actual. Silencio y diálogo entre generaciones. Madrid-Frankfurt, Iberoamericana-Vervuert, 2010, p. 14. 
Aínda que poidamos non coincidir de maneira estrita coa distinción feita por Assmann entre memoria comunicativa e cultural, de considerarmos que á literatura lle corresponde un papel importante na construción da memoria cultural dos galegos, é significativo o feito de que boa parte das creacións narrativas actuais - producidas no contexto do movemento de recuperación da memoria histórica - boten man nas súas historias da memoria oral, comunicativa, como forma de transmitir o pasado ou de acceder a el por parte dos personaxes que conforman a acción habitualmente localizada no presente. Se consideramos que a sociedade galega actual se atopa nesa transición da memoria comunicativa á cultural, as propias ficcións destas novelas - medios- de memoria cultural - virían representar ese proceso transicional cara á memoria cultural como único modo posíbel de conservación dese pasado no futuro. Cremos, ademais, que os procedementos metaliterarios de que se valen a miúdo estes relatos veñen reflexionar sobre a relación e a pegada do pasado no presente, sobre a xestión da memoria e o esquecemento na sociedade actual e sobre a propia produción da memoria cultural a través da literatura, así como sobre as funcións de almacenamento e circulación que Erll lle atribúe.

Segundo José María Izquierdo, "lo que hacen los autores de la novela de la memoria de la Guerra civil no es más que la simulación de la figura del archivero en La mémoire, l'histoire, l'oubli de Ricoeur (2003), es decir, transcribiendo los testimonios orales para su archivado, clasificación y acceso"26. Neste sentido, é interesante ver como os testemuños orais, alén das súas representacións ficcionais no interior das diéxeses narrativas, son a miúdo unha das fontes principais no proceso de documentación dos autores para a escritura das obras. En especial aqueles relatos que pretenden rescatar episodios reais que foran silenciados, beben da tradición oral, dunha memoria reprimida que a través dos escritores - convertidos nunha especie de mediadores - consegue saír á luz. Como xa ten sido anotado nalgún momento, son habituais os prólogos ou notas paratextuais nas novelas da memoria que recollen con frecuencia información deste tipo e, ao tempo, dan conta da vontade de intervención na esfera pública que adoita animar os seus autores ${ }^{27}$. É o caso, por exemplo, dos "Agradecementos" que pechan a novela Non hai noite tan longa, onde Fernández Paz revela, ademais dalgunhas das súas fontes historiográficas, que foi a memoria viva da xente daquel tempo que pretendeu retratar a súa principal fonte de inspiración e documentación.

${ }^{26}$ J.M. Izquierdo, "Escribir de oídas. Última literatura de la memoria de la Guerra civil española y su posguerra", en: E. Ahlstedt, K. Benson et al. (eds.), Actes du XVIII congrès des romanistes scandinaves. Romanica Gothoburgensia, Göteborg, Acta Universitatis Gothoburgensis, 2012, p. 385. P. Ricoeur, La memoria, la historia, el olvido, Madrid, Trotta, 2003.

27 D. Vilavedra, "A Guerra Civil na narrativa galega: un ámbito moral”, Grial, 170, 2006, pp. 118-123. 


\section{Referencias bibliográficas}

ALBERT Mechthild

2006 "Oralidad y memoria en la novela memorialística", en: Winter U. (ed.), Lugares de memoria de la guerra civil y el franquismo, Madrid-Frankfurt, Iberoamericana-Vervuert, pp. 21-38.

ASSMANN Jan

2008 "Communicative and Cultural Memory", en: Erll A., Nünning A. (eds.), Cultural Memory Studies. An International and Interdisciplinary Handbook, Berlin-New York, Walter de Gruyter, pp. 109-118.

BUNGÅRD Ana

2012 "Registros de la imaginación utópica en la ficción memorialista española actual: El lápiz del carpintero, Soldados de Salamina y Anatomía de un instante", en: Hansen H.L., Cruz Suárez J.C. (eds.), La memoria novelada. Hibridación de géneros y metaficción en la novela española sobre la guerra civil y el franquismo (2000-2010), Berna, Peter Lang, pp. 107-124.

CORREDERA GONZÁLEZ María

2010 La guerra civil española en la novela actual. Silencio y diálogo entre generaciones. Madrid-Frankfurt, Iberoamericana-Vervuert.

DOMÍNGUEZ ALMANSA Andrés, SOMOZA CAYADO Antonio

2013 "Víctimas y memoria del 36: De la resistencia callada al voto en la transición", Memória Antifranquista Del Baix Llobregat, 9 (13), pp. 74-77.

ERLL Astrid

2008 "Cultural Memory Studies. An Introduction", en: Erll A., Nünning A. (eds.), Cultural Memory Studies. An International and Interdisciplinary Handbook, Berlin-New York, Walter de Gruyter, pp. 1-18.

2011 Memory in Culture, Hampshire, Palgrave Macmillan.

FERNÁNDEZ PRIETO Lourenzo

2009 "Actitudes sociales y políticas en la denominada recuperación de la memoria histórica. Galicia. El proyecto de investigación interuniversitario «Nomes e voces»”, Pasado y Memoria, 8, pp. 131-157.

HANSEN Hans Lauge

2012 "Formas de la novela histórica actual", en: Hansen H.L., Cruz Suárez J.C. (eds.), La memoria novelada. Hibridación de géneros y metaficción en la novela española sobre la guerra civil y el franquismo (2000-2010), Berna, Peter Lang, pp. 83-103.

IZQUIERDO José María

2012 "Escribir de oídas. Última literatura de la memoria de la Guerra civil española y su posguerra", en: Ahlstedt E., Benson K., Bladh E., Söhrman I., Åkerström U. (eds.), Actes du XVIII congrès des romanistes scandinaves. Romanica Gothoburgensia, Göteborg, Acta Universitatis Gothoburgensis, 2012, pp. 385-398.

KORTAZAR Jon

2008 "Memoria y Guerra civil en la narrativa vasca (1948-2007)", en: Repositorio institucional UNLP, <http://sedici.unlp.edu.ar/handle/10915/16283>, 26 de abril de 2018.

LIIKANEN Elina

2012 "Pasados imaginados. Políticas de la forma literaria en la novela española sobre la guerra civil y el franquismo", en: Hansen H.L., Cruz Suárez J.C. (eds.), La memoria novelada. Hibridación de géneros y metaficción en la novela española sobre la guerra civil y el franquismo (2000-2010), Berna, Peter Lang, pp. 43-53.

\section{LUENGO Ana}

2012 La encrucijada de la memoria, Berlín, Tranvía.

RICOEUR Paul

2003 La memoria, la historia, el olvido, Madrid, Trotta. 
SÁNCHEZ Mariela

2018 Mala herencia la que nos ha tocado: oralidad y narrativa en la literatura sobre la Guerra Civil y el franquismo, Santiago de Compostela, USC Editora Académica.

SÁNCHEZ ZAPATERO Javier

2016 "Detectives de la memoria: la novela negra como medio de indagación en la historia reciente española", Ciberletras, 26, pp. 1-5.

THOMPSON John

2009 As novelas da memoria. Trauma e representación da historia na Galiza contemporánea, Vigo, Galaxia.

VILAVEDRA FERNÁNDEZ Dolores

2006 “A Guerra Civil na narrativa galega: un ámbito moral”, Grial, 170, pp. 118-123.

2015 "Literatura en el espacio público. Rivas y su obra: un punto de inflexión en la recuperación de la memoria histórica", Olivar, 16 (24), pp. 1-17.

\section{Voices of memories: Oral memory, traumatic past and the novel in contemporary Galicia}

Keywords: cultural memory — oral memory — Galician narrative — Francoism.

\section{Abstract}

The fictionalisation of the Spanish Civil War and Francoism in the Galician novel has experienced a significant evolution from a thematic and formal point of view. This evolution has been greatly influenced by the memory boom since the beginning of the 21 st century, both in Galicia and the rest of Spain. Therefore, exploring the contemporary Galician narrative corpus requires an interdisciplinary approach to address not only the literary representations of history and memory, but also the functions acquired by those narratives in connection with the context as well as the cultural memory of the Galician people. This paper focuses on the relationship between memory and orality in some of these texts in order to analyse how oral memory emerges in the novel as a form of persistence of the past in current times. This oral memory becomes a key element in many of these narratives and faces a deliberate collective amnesia and the reluctance to remember, acting as a space for resistance that connects the past and present in the texts.

Fecha de recepción: 8.05.2018

Fecha de aceptación: 19.11.2018 